\title{
Canopy Hyperspectral Reflectance of Redroot Pigweed versus Okra and Super Okra Leaf Cotton
}

\author{
Reginald S. Fletcher \\ Agricultural Research Service, United States Department of Agriculture, Stoneville, USA \\ Email: reginald.fletcher@usda.gov
}

How to cite this paper: Fletcher, R.S. (2019) Canopy Hyperspectral Reflectance of Redroot Pigweed versus Okra and Super Okra Leaf Cotton. Agricultural Sciences, 10, 14651476.

https://doi.org/10.4236/as.2019.1011107

Received: September 25, 2019

Accepted: November 18, 2019

Published: November 21, 2019

Copyright (๑) 2019 by author(s) and Scientific Research Publishing Inc. This work is licensed under the Creative Commons Attribution International License (CC BY 4.0).

http://creativecommons.org/licenses/by/4.0/

\begin{abstract}
Redroot pigweed (Amaranthus retroflexus L.) is a nuisance weed that affects cotton (Gossypium hirsutum L.) growth and yield worldwide. Being able to distinguish redroot pigweed from cotton would help producers and crop consultants better implement strategies used to suppress and control it. Hyperspectral reflectance properties of weed and crop canopies have been used to differentiate between them. Currently, no information is available on the application of hyperspectral data to distinguish redroot pigweed from cotton with different leaf shapes. Positive results will further support the exploration of remote sensing technology for distinguishing redroot pigweed from cotton. The objectives were to compare canopy hyperspectral reflectance of redroot pigweed to canopy hyperspectral reflectance of okra and super okra leaf cotton and to identify regions of the spectrum in which differences exist in their reflectance properties. Hyperspectral reflectance measurements of redroot pigweed and cotton were obtained with a spectroradimeter on May 6 and June 27, 2019. Plants grown in a greenhouse were used for this study. One-hundred and sixty-two 10-nm bands (400 - $2350 \mathrm{~nm}$ spectral range) were evaluated with analysis of variance $(p \leq 0.05)$ and Dunnett's test $(p \leq 0.05)$ to determine the wavebands that were useful for separating redroot pigweed from okra leaf and super okra leaf cotton. The following bands were consistent in distinguishing redroot pigweed and okra leaf cotton on both dates: $420 \mathrm{~nm}, 510-650 \mathrm{~nm}, 690-740 \mathrm{~nm}$, and $2000-2010$ $\mathrm{nm}$; whereas, $400-500 \mathrm{~nm}, 1480-1780 \mathrm{~nm}$, and 1990 - $2350 \mathrm{~nm}$ were identified for both dates for separating redroot pigweed from super okra leaf cotton. Commercial imaging systems used on ground-based or airborne platforms can be easily tuned into the spectral bands listed in this study, thus providing managers with a tool to use for identifying redroot pigweed in cotton production systems.
\end{abstract}




\section{Keywords}

Amaranthus retroflexus, Gossypium hirsutum, Visible, Red Edge, Shortwave Infrared

\section{Introduction}

Cotton is grown worldwide for its fiber production and is used more than any other fiber producing plant [1]. Cotton production contributes enormously to the agricultural sector because of the supplies purchased to grow it. Furthermore, cotton is used to make clothing, bedding, plastics, paper products, furniture, automobile cushions, cottonseed oil, animal feed, fertilizers, and explosives. After the growing season, its stalks are plowed under to enrich the soil. Weed infestation is a common problem in a cotton production system because it reduces cotton growth and yield.

Redroot pigweed, one of the most invasive weeds in agricultural production worldwide [2], is known to reduce yields in bean species (Phaseolus spp.) [3] [4] [5], soybean (Glycine max L.) [6], corn (Zea mays L.) [7] [8] [9], and cotton [10] [11] [12]. It is a nuisance because one plant produces thousands of seeds, ensuring the next generation of plants [13]. If seeds are present in the soil and environmental conditions ideal for seed germination, then redroot pigweed seeds will sprout throughout the growing season [14], requiring multiple treatments to control it. If new plants are allowed to mature, then they will add more seeds to the seed bank. Redroot pigweed seeds are viable for a long time thus requiring treatment for many years after an infestation [15] [16].

Redroot pigweed grows quickly allowing it to outcompete agricultural plants for water and nutrients. Its allelopathic characteristics also give it an advantage in crop production systems [17] [18] [19]. Redroot pigweed has developed resistance to acetolactate synthase (ALS) inhibitors, photosystem II inhibitors (PSII), and protoporphyrinogen oxidase (PPO) [20] in some areas of the world, making it a challenge to control. Redroot pigweed can grow up to $3 \mathrm{~m}$ tall. Therefore, it is a tall weed. Tall weeds tend to be more damaging to cotton growth and development [21] because they cover the shorter cotton plant canopies. The light reaching the shorter cotton plants is reduced causing them not to be able to compete for water and nutrients at the same level as the weed.

Redroot pigweed can reduce cotton yield by $5 \%-90 \%$ percent [10] [11] [12]; plant density of the redroot pigweed and soil pattern are associated with its effects on cotton yield [10] [11] [12]. Producers and crop consultants are seeking tools to help them identify redroot pigweed in cotton production systems. Being able to distinguish redroot pigweed from cotton would help producers and crop consultants better implement strategies used to suppress and control it.

Spectral reflectance properties of weed and crop canopies have been used to differentiate between them. Advances in multispectral and hyperspectral tech- 
nologies have increased the use of remote sensing technologies in weed crop discrimination. Little canary grass (Phalaris minor Retz.) [22], button weed (Malva neglecta) [23], and spiny emex (Rumex spinosus L.) [24] [25] were distinguished from wheat (Triticum aestivum L.), based on their red and near infrared canopy reflectance. Those studies focused on using the red and near infrared bands as a ratio and a normalized difference vegetation index. Furthermore, the findings of those studies indicated that pure populations of little canary grass, button weed, and spiny emex were distinguishable from pure wheat stands 34,30 , and 30 days after planting, respectively. Also, different population levels of button weed and spiny emex were discernable from themselves 60 days after planting based on their reflectance properties; density levels of little canary grass were separable from themselves 68 days after planting using the reflectance data. The differences in the weed populations reflectance were detectable up to 120 days after planting.

Researchers have used spectral reflectance data of crop canopies as input in various classification algorithms for crop and weed separation. Reference [26] distinguished wild oat (Avena sterilis L.) and canary grass in wheat fields using multispectral, hyperspectral, and vegetation index data and discriminate analysis. Reference [27] demonstrated that multispectral data could be used as input into random forest classifier to distinguish velvetleaf (Abutilon theophrasti Medic.) from soybean [Glycine max L. (Merr.)]; reference [28] showed that hyperspectral data and random forest was useful for separating Palmer amaranth (Amaranthus palmeri S. Wats.) from cotton with different colored leaves. Reference [29] discriminated Barnyard grass [Echinochloa crus-galli (L.) P. Beauv], green foxtail [Setaria viridis (L.) P. Beauv], goosegrass [Eleusine indica (L.) Gaertn], crabgrass (Digitaria sanguinalis L.), and quinoa (Chenopodium quinoa Willd.) from cabbage (Brassica oleracea L.) using hyperspectral reflectance data as input into Bayesian discriminant analysis.

As indicated earlier, spectral reflectance properties of plant canopies have been used to distinguish crops from weeds. Understanding these properties is often the basic premise for implementing remote sensing technology for weed detection and mapping in agricultural systems. Also, by conducting these studies, researchers can determine if more information is needed to enhance the spectral information for crop weed discrimination. Reference [30] have published research on the difference in reflectance properties of Palmer amaranth, another pigweed, versus okra and super okra leaf cotton. Currently, no information is available on the application of hyperspectral data to distinguish redroot pigweed from cotton with different leaf shapes. The objectives were to compare canopy hyperspectral reflectance of redroot pigweed to canopy hyperspectral reflectance of okra and super okra leaf cotton and to identify regions of the spectrum in which differences exist in their reflectance properties. The study specifically focused on comparing visible, red edge, near infrared, and shortwave infrared reflectance properties of the plant canopies. 


\section{Materials and Methods}

\subsection{Study Site, Planting Dates, Experimental Design}

The experiment was conducted in a greenhouse located at the United States Department of Agriculture, Agricultural Research Service Facility, Stoneville, MS (33.425261 latitude, -90.912740 longitude). Redroot pigweed, okra leaf cotton, and super okra leaf cotton seeds were bulk planted into seed trays (Garland, Standard Half Size Seed Trays, Greenhouse Megastore, Danville, IL, 1 seed tray for each plant type) filled with commercial potting mix (Pro-Mix BX general professional growth medium, Premier Tech Horticulture, Quakertown, PA). Planting dates were February 27 and May 13, 2019, for experiments one and two, respectively. Ten days after emergence healthy plants were transplanted to 2-liter pots (Belden Jumbo Senior Square Pots, Greenhouse Mega, Danville, IL) containing the same commercial potting mix. Plants were subjected to 14-hour day length; sodium vapor lamps (average luminous flux $=84,100$ ) were used as supplemental lighting in the mornings (6:00AM - 8:00AM) and the evenings (6:00PM - 8:00PM). The greenhouse temperature was maintained within the following range: $21.1^{\circ} \mathrm{C}$ and $26.7^{\circ} \mathrm{C}$. Redroot pigweed, okra leaf cotton, and super okra leaf cotton seeds were obtained from seed banks maintained by scientists working at the Stoneville laboratory. The redroot pigweed was not resistant to any herbicides. The plants were watered and fertilized (Dyna-Gro All-Pro 7-7-7, Richmond, CA) weekly. The experimental design was a randomized complete block design consisting of fifteen blocks and three treatments per block (i.e., plantsredroot pigweed, okra leaf cotton, and super okra leaf cotton).

\subsection{Reflectance Measurements}

Reflectance measurements of the plant canopies were acquired on May 6, 2019, and June 27, 2019, \pm 2 hours of solar noon [31] for experiments one and two, respectively. They were obtained with a FieldSpec 3 Full Range Hyperspectral Spectroradiometer (Analytical Spectral Devices, Malvern Panalytical, Boulder, $\mathrm{CO}$ ). The spectroradiometer collected spectral data in the 350 - $2500 \mathrm{~nm}$ spectral range. Its sensor was placed nadir $30.48 \mathrm{~cm}$ above the plant canopy to obtain the reflectance measurements. At that height, the sensor's ground field of view was $13.5 \mathrm{~cm}$. For each plant, the reflectance measurement was an average of fifteen scans obtained by the spectroradiometer. Calibration of the instrument was completed at 15-minute intervals with a white spectralon reflectance panel (Analytical Spectral Devices, Malvern Panalytical, Boulder, Colorado). The plants were taken outside of the greenhouse to obtain the measurements; instrument calibration and reflectance measurements were acquired under sunny conditions. As described in [30], black felt was used to cover the potting mix background and to serve as the background surface for placing the pots. Its reflectance value was approximately $3 \%$ in all regions of spectrum evaluated in this study. 
The goal of the study was to obtain reflectance measurements of the redroot pigweed and the cotton during the vegetative growth stage. Once pigweed plants start to seed, it is difficult to control them with herbicides. The redroot pigweed was at the fifteenth and sixteenth leaf stage for experiments one and two, respectively. Okra and super okra leaf cotton plants were at the ninth and eight leaf stage for first the experiment. For the second experiment, the plants were developing squares. Weather conditions hindered data being collected earlier, preferably between the fourth and fifth leaf stage for the cotton.

\subsection{Preparing Hyperspectral Data for Analysis}

The data were processed using the following steps [30] [32]: 1) splice correction of the spectra, 2) removal of water absorption bands (i.e., 1330 - $1480 \mathrm{~nm}, 1780$ $1990 \mathrm{~nm}$ ), 3) elimination of noisy data and spectral bands commonly not used for remote sensing (i.e., $350-400 \mathrm{~nm}, 2360$ - $2500 \mathrm{~nm}$ ), 4) smoothing the spectra with the Savitizky-Golay [33] filter $(n=25$, number points used for data smoothing), and 5) aggregating the 1-nm spectral bands recorded by spectroradiometer to $10-\mathrm{nm}$ spectral bands. Splice correction was completed with the ViewSpec Pro Software (Version 6.2, Analytical Spectral Devices, Malvern Panalytical Boulder, $\mathrm{CO}$ ). Steps two thru four above were completed with the $\mathrm{R}$ software (Version 3.6.1, "Action of the Toes" [34]) HSDAR package [35].

\subsection{Statistical Analyses}

For each waveband, analysis of variance (ANOVA, $p \leq 0.05$ ) was used to determine if reflectance differences were statistically significant among the plant group means [36] [37]. If yes, then the Dunnett's test [38] was used to determine if a statistically significant $(p \leq 0.05)$ difference existed between redroot pigweed and okra leaf cotton, and redroot pigweed and super okra leaf cotton. For experiment one, a redroot pigweed plant died. Therefore, 14 blocks were analyzed for that experiment. The agricolae package [39] of the R software was used to complete the ANOVA and Dunnett's analyses.

\section{Results}

Mean hyperspectral reflectance curves of redroot pigweed and okra and super okra leaf cotton canopies are shown in Figure 1 for the two experiments. Overall, okra leaf cotton canopies mean reflectance values were greater than the redroot pigweed canopies mean reflectance values in the visible, red edge, and near infrared regions of the light spectrum. Super okra leaf cotton canopies mean reflectance values were less than redroot pigweed canopies mean reflectance values in the near infrared and the shortwave infrared regions of the light spectrum for both sets of measurements.

Based on the ANOVA, statistically significant differences $(p \leq 0.05)$ were observed among the plant groups for all 162 bands evaluated (Table 1). Further exploration of the bands with the Dunnett's test identified 95 and 31 spectral 
bands with statistically significant $(p \leq 0.05)$ differences between redroot pigweed and okra leaf cotton reflectance for the May and the June measurements, respectively (Table 2). For the redroot pigweed and super-okra leaf cotton comparison, the Dunnett's test identified 85 and 99 spectral bands in which the differences in reflectance values were statistically significant $(p \leq 0.05)$ for the May and June measurements, respectively (Table 2).

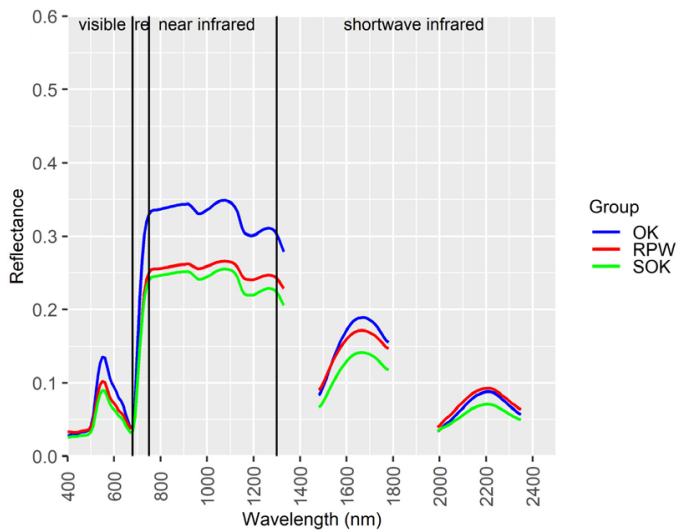

(a)

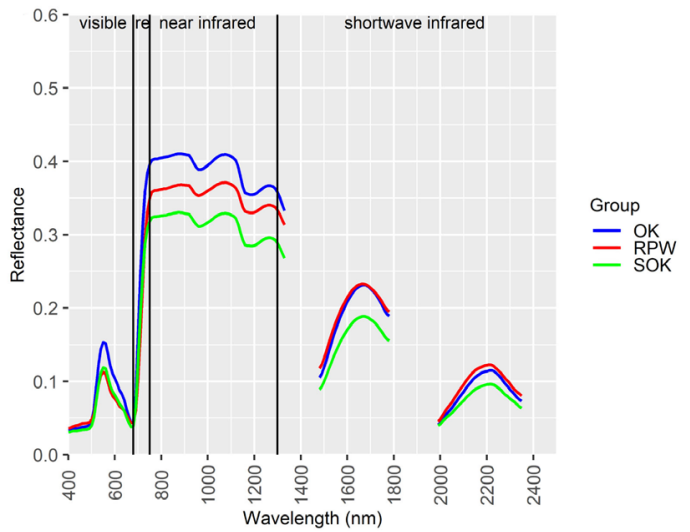

(b)

Figure 1. Mean canopy hyperspectral reflectance spectrum of okra leaf cotton (OK), redroot pigweed (RPW), and super okra leaf cotton (SOK) obtained on (a) May 6, 2019 (n $=14)$ and $(\mathrm{b})$ June 27, $2019(\mathrm{n}=15)$. red = red edge.

Table 1. Analysis of variance $(p \leq 0.05)$ results listing the spectral regions, spectral bands, and number of bands in which statistical differences were observed among redroot pigweed, okra leaf cotton, and super okra leaf cotton canopy reflectance.

\begin{tabular}{cccc}
\hline Date & Spectral Region & Spectral Bands (nm) & Number of Bands \\
\hline May 6, 2109; June 27, 2019 & Visible & $400-670$ & 28 \\
& Red edge & $680-750$ & 8 \\
& Near infrared & $760-1300$ & 55 \\
& & $1310-1330 ;$ & 71 \\
& Shortwave infrared & $1480-1780 ;$ & 162 \\
& & $1990-2350$ & \\
\hline
\end{tabular}


Table 2. Dunnett's test $(p \leq 0.05)$ results listing the spectral regions, spectral bands, and the number of bands in which statistical differences occurred between redroot pigweed (RPW) versus okra leaf cotton (OK) comparison and redroot pigweed versus super okra leaf cotton (SOK) comparison.

\begin{tabular}{|c|c|c|c|c|}
\hline Date & Comparison & Spectral Region & Spectral Bands (nm) & Number of Bands \\
\hline \multirow[t]{11}{*}{ May 6, 2019} & RPW vs OK & Visible & $400-420 ; 510-650$ & 18 \\
\hline & & Red edge & $690-750$ & 7 \\
\hline & & Near infrared & $760-1300$ & 55 \\
\hline & & & 1310 - 1330; & \\
\hline & & Shortwave infrared & $\begin{array}{c}1990-2090 \\
2350\end{array}$ & 15 \\
\hline & & & Total & 95 \\
\hline & RPW vs SOK & Visible & $400-520 ; 650-670$ & 16 \\
\hline & & Red edge & 680 & 1 \\
\hline & & Near infrared & & 0 \\
\hline & & Shortwave infrared & $1480-1780 ; 1990-2350$ & 68 \\
\hline & & & Total & 85 \\
\hline \multirow[t]{10}{*}{ June 27, 2019} & RPW vs OK & Visible & $420-490,510-650$ & 23 \\
\hline & & Red edge & $690-740$ & 6 \\
\hline & & Near infrared & & 0 \\
\hline & & Shortwave infrared & $2000-2010$ & 2 \\
\hline & & & Total & 31 \\
\hline & RPW vs SOK & Visible & $400-500$ & 11 \\
\hline & & Red edge & $670-680,700-710$ & 4 \\
\hline & & Near infrared & $1160-1300$ & 15 \\
\hline & & Shortwave infrared & $\begin{array}{l}1310-1330 \\
1480-1780 \\
1990-2350\end{array}$ & 69 \\
\hline & & & Total & 99 \\
\hline
\end{tabular}

For the May 6 and June 27, 2019 dates, the following bands were consistent in distinguishing redroot pigweed and okra leaf cotton: $420 \mathrm{~nm}, 510-650 \mathrm{~nm}, 690$ - $740 \mathrm{~nm}$, and $2000-2010 \mathrm{~nm}$ (Table 2). Bands in which the reflectance value differences were statistically significant $(p \leq 0.05)$ for the redroot pigweed and super okra leaf cotton comparison on both dates were $400-500 \mathrm{~nm}, 1480$ - 1780 $\mathrm{nm}$, and 1990 - $2350 \mathrm{~nm}$ (Table 2). The $420 \mathrm{~nm}$ and 2000 - $2010 \mathrm{~nm}$ spectral bands were considered universal because reflectance differences were statistically significant for redroot pigweed and both cotton comparisons on both dates (Table 2).

\section{Discussion}

Spectral bands within the visible, red edge, and shortwave infrared regions of the 
light spectrum were identified for distinguishing redroot pigweed from okra leaf and super okra leaf cotton (Table 2). Various plant components influence visible, red edge, and shortwave infrared reflectance properties of plant leaves [40] [41]. Plant pigments are the major contributor to leaf reflectance spectral responses in the visible region of the light spectrum [40] [41]. A combination of plant pigments and intercellular spaces within the plant leaves and multiple leaf layers affects the red edge response of plant leaves and canopies [42]. Water content within the plant leaves causes the differences observed in the shortwave infrared reflectance properties of plant leaves and canopies [40] [41]. Thus, leaf pigment, intercellular spaces in plant leaves, multiple leaf layers in the plant canopies, and leaf water content caused the spectral differences observed between redroot pigweed and the cotton canopies.

Near infrared reflectance data were inconsistent in separating redroot pigweed and the cotton plants. Similar results were observed by [30] for near infrared spectra in comparison of Palmer amaranth, another common pigweed, and okra leaf and super okra leaf cotton.

Also, in-canopy shadowing and background affected differences observed between redroot pigweed and okra and super okra leaf cotton. Their contribution is based on the architecture of the plant canopies (Figure 2). Redroot pigweed and okra leaf cotton canopies consisted of broad leaves that have a horizontal leaf orientation; whereas, super okra leaf cotton canopies have narrow leaves and a horizontal leaf orientation. Furthermore, spaces between the plant leaves contributed to the reflectance differences observed between the redroot pigweed and okra and super okra leaf cotton canopies. More open spaces equal more shadows and background being recorded by the sensor, causing a decrease in the reflectance of the plant canopies.

Twenty spectral bands were identified by [43] as optimal for vegetation mapping: $490 \mathrm{~nm}, 515 \mathrm{~nm}, 531 \mathrm{~nm}, 550 \mathrm{~nm}, 570 \mathrm{~nm}, 682 \mathrm{~nm}, 720 \mathrm{~nm}, 855 \mathrm{~nm}, 910$ $\mathrm{nm}, 970 \mathrm{~nm}, 1075 \mathrm{~nm}, 1180 \mathrm{~nm}, 1245 \mathrm{~nm}, 1450 \mathrm{~nm}, 1650 \mathrm{~nm}, 1725 \mathrm{~nm}, 1950$ $\mathrm{nm}, 2205 \mathrm{~nm}, 2260 \mathrm{~nm}$, and $2359 \mathrm{~nm}$. For redroot pigweed versus okra leaf cotton comparison, $510-650 \mathrm{~nm}$ and $690-740 \mathrm{~nm}$ spectral bands were similar to the optimal spectral bands; for the redroot pigweed versus the super okra leaf comparison, $420 \mathrm{~nm}, 1450 \mathrm{~nm}, 1650 \mathrm{~nm}, 1720-1730 \mathrm{~nm}, 2200-2210 \mathrm{~nm}$, and

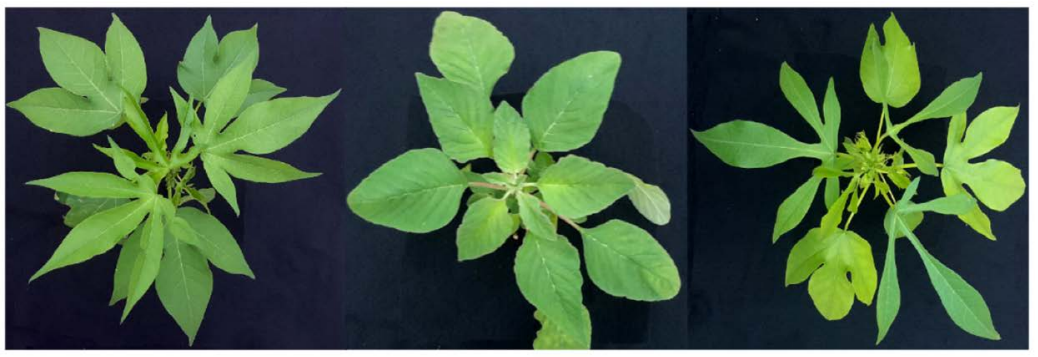

(a)

(b)

(c)

Figure 2. Overhead example of (a) okra leaf cotton; (b) redroot pigweed; and (c) super okra leaf cotton canopies. 
$2260 \mathrm{~nm}$ spectral bands were comparable to the optimal spectral bands. The optimal spectral bands discussed by [43] were based on $5 \mathrm{~nm}$ bandwidths in comparison to the $10 \mathrm{~nm}$ bandwidths used for the current study.

Multispectral camera systems can be tuned into the spectral bands identified for differentiating redroot pigweed from okra and super okra leaf cotton. Sensors sensitive to visible, red edge, and near infrared light are inexpensive to purchase and build compared to systems sensitive to visible, red edge, near infrared, and shortwave infrared light. The difference in cost is attributed to the shortwave infrared sensor. Shortwave infrared sensors are constructed from indium gallium arsenide, which is more expensive than silicon material used to construct visible, red edge, and near infrared-sensitive sensors. For example, a single camera sensitive to shortwave infrared reflectance cost more than $\$ 20,000$.

Overall, a hyperspectral camera system may be more beneficial in that commercial systems often acquire data in wavebands similar to the ones evaluated in this study. Also, it would not be limited to the weed and crop tested in this study. However, the same rule applies to cost. Visible, red edge, and near infrared sensitive hyperspectral systems are much cheaper than visible, red edge, near infrared, and shortwave infrared sensitive hyperspectral systems.

\section{Conclusion}

This study focused on using canopy hyperspectral reflectance measurements as a means for distinguishing redroot pigweed from okra and super okra leaf cotton. The results indicated that it could be distinguished from okra leaf and super okra leaf cotton based on its canopy hyperspectral reflectance properties. Spectral bands within the visible, red edge, and shortwave infrared regions of the light spectrum were determined to be optimal for redroot pigweed and okra and super okra leaf cotton separation. There are commercial imaging systems designed for ground-based or airborne platforms that can be easily tuned into the spectral bands listed in this study, thus providing managers with a tool to use in precision agriculture applications of redroot pigweed in cotton production systems.

\section{Acknowledgements}

The author would like to thank Dr. Ricky Turley, Dr. Vijay Nandula, Milton Gaston Jr., Destraile Jackson, Mekaela Brisco, and Eric Benson for their assistance in this study. Mention of a trade name, proprietary product, or specific equipment does not constitute a guarantee or warranty by the United States Department of Agriculture and does not apply endorsement of a product to the exclusion of others that may be suitable.

\section{Conflicts of Interest}

The author declares no conflicts of interest regarding the publication of this paper. 


\section{References}

[1] Cotton Counts (2019) The Story of Cotton.

https://www.cotton.org/pubs/cottoncounts/story/upload/The-Story-of-Cotton-Hi-R es-642k-PDF.pdf

[2] Horak, M.J. and Loughin, T.M. (2000) Growth Analysis of Four Amaranthus Species. Weed Science, 48, 347-355. https://doi.org/10.1614/0043-1745(2000)048[0347:GAOFAS]2.0.CO;2

[3] Aguyoh, J.N. and Masiunas, J.B. (2003) Interference of Redroot Pigweed (Amaranthus retroflexus) with snap beans. Weed Science, 51, 202-207. https://doi.org/10.1614/0043-1745(2003)051[0202:IORPAR]2.0.CO;2

[4] Amini, R., Alizadeh, H. and Yousefi, A. (2014) Interference between Red Kidney Bean (Phaseolus vulgaris L.) Cultivars and Redroot Pigweed (Amaranthus retroflexus L.). European Journal of Agronomy, 60, 13-21. https://doi.org/10.1016/j.eja.2014.07.002

[5] Mirshekari, B., Javanshir, A. and Arbat, H.K. (2010) Interference of Redroot Pigweed (Amaranthus retroflexus) in Green Bean (Phaseolus vulgaris). Weed Biology and Management, 10, 120-125. https://doi.org/10.1111/j.1445-6664.2010.00371.x

[6] Bensch, C.N., Horak, M.J. and Peterson, D. (2003) Interference of Redroot Pigweed (Amaranthus retroflexus), Palmer Amaranth (A. palmeri), and Common Waterhemp (A. rudis) in soybean. Weed Science, 51, 37-43. https://doi.org/10.1614/0043-1745(2003)051[0037:IORPAR]2.0.CO;2

[7] Knezevic, S.Z., Weise, S.E. and Swanton, C.J. (1994) Interference of Redroot Pigweed (Amaranthus retroflexus) in Corn (Zea mays). Weed Science, 42, 568-573. https://doi.org/10.1017/S0043174500076967

[8] Sheibany, K., Meybodi, M.A.B. and Atri, A. (2009) Competitive Effects of Redroot Pigweed (Amaranthus retroflexus) on the Growth Indices and Yield of Corn. Weed Biology and Management, 9, 152-159. https://doi.org/10.1111/j.1445-6664.2009.00333.x

[9] Ghanizadeh, H., Lorzadeh, S. and Aryannia, N. (2014) Effect of Weed Interference on Zea mays: Growth Analysis. Weed Biology and Management, 14, 133-137. https://doi.org/10.1111/wbm.12041

[10] Buchanan, G.A. and Burns, E.R. (1971) Weed Competition in Cotton. II . Cocklebur and Redroot Pigweed. Weed Science, 19, 580-582. https://doi.org/10.1017/S0043174500050736

[11] Buchanan, G.A., Crowley, R.H., Street, J.E. and McGuire, J.A. (1980) Competition of Sicklepod (Cassia obtusifolia) and Redroot Pigweed (Amaranthus retroflexus) with Cotton (Gossypium hirsutum). Weed Science, 28, 258-262. https://doi.org/10.1017/S0043174500055259

[12] Ma, X., Wu, H., Jiang, W., Ma, Y. and Ma, Y. (2015) Interference between Redroot Pigweed (Amaranthus retroflexus L.) and Cotton (Gossypium hirsutum L.): Growth Analysis. PLoS ONE, 10, e0130475. https://doi.org/10.1371/journal.pone.0130475

[13] Knezevic, S.Z. and Horak, M.J. (1998) Influence of Emergence Time and Density on Redroot Pigweed (Amaranthus retrofexus). Weed Science, 46, 665-672. https://doi.org/10.1017/S0043174500089694

[14] Karimmojeni, H., Bazrafshan, A.H., Majidi, M.M., Torabian, S. and Rashidi, B. (2014) Effect of Maternal Nitrogen and Drought Stress on Seed Dormancy and Germinability of Amaranthus retroflexus. Plant Species Biology, 29, e1-e8. https://doi.org/10.1111/1442-1984.12022 
[15] Burnside, O.C., Wilson, R.G., Weisberg, S. and Hubbard, K. (1996) Seed Longevity of 41 Weed Species Buried 17 Years in Eastern and Western Nebraska. Weed Science, 44, 74-86. https://doi.org/10.1017/S0043174500093589

[16] Telewski, F.W. and Zeevaart, J.A.D. (2002) The 12-Years Period for Dr. Beal's Seed Viability Experiment. American Journal of Botany, 89, 264-270. https://doi.org/10.3732/ajb.89.8.1285

[17] Jalali, M., Motlagh, B.P. and Salari, K. (2012) Allelopathic Effects of Aqueous Extract of Shoot and Root of Licorice (Glycyrrhiza glabra L.) and Pigweed (Amaranthus retroflexus L.) on Germination Characteristic and Seedling Growth of Corn and Chickpea. International Journal of Agricultural Research and Reviews, 2, 357-363.

[18] Knezevic, S.Z., Horak, M.J. and Vanderlip, R.L. (1997) Relative Time of Redroot Pigweed (Amaranthus retroflexus L.) Emergence Is Critical in Pigweed Sorghum [Sorghum bicolor (L.) Moench] Competition. Weed Science, 45, 502-508. https://doi.org/10.1017/S0043174500088731

[19] Rezaie, F. and Yarnia, M. (2009) Allelopathic Effects of Chenopodium album, Amaranthus retroflexus and Cynodon dactylon on Germination and Growth of Safflower. Journal of Food, Agriculture, and Environment, 7, 516-521.

[20] Heap, I. (2019) International Survey of Herbicide Resistant Weeds. http://www.weedscience.org

[21] Chandler, J.M. (1977) Competition of Spurred Anoda, Velvetleaf, Prickly Sida, and Venice Mallow in Cotton. Weed Science, 25, 151-158. https://doi.org/10.1017/S0043174500033154

[22] Kaur, R., Mahey, R.K. and Mukherjee, J. (2010) Optimum Time Span for Distinguishing Little Canary Grass (Phalaris minor) from Wheat (Triticum aestivum) Crop Based on Their Spectral Reflectance Characteristics. Indian Journal of Agricultural Sciences, 80, 615-619.

[23] Kaur, R. and Jaidka, M. (2014) Spectral Reflectance Characteristics to Distinguish Malva neglecta in Wheat (Triticum aestivum). Indian Journal of Agricultural Sciences, 84, 1243-1249.

[24] Kaur, R., Jaidka, M. and Kingra, P.K. (2013) Study of Optimum Time Span for Distinguishing Rumex spinosus in Wheat Crop through Spectral Reflectance Characteristics. Proceedings of the National Academy of Sciences, India Section B: Biological Sciences, 84, 625-633. https://doi.org/10.1007/s40011-013-0255-x

[25] Buttar, G.S. Kaur, T., Kaur, R. and Kalra, V.P. (2017) Effect of Different Densities of Rumex spinosus on Growth and Yield of Wheat (Triticum aestivum) and Spectral Characteristics of Rumex spinosus. Indian Journal of Agronomy, 62, 185-190.

[26] Gómez-Casero, M.T., Castillejo-González, I.L., García-Ferrer, A., Peña-Barragán, J.M., Jurado-Expósito, M., García-Torres, L. and López-Granados, F. (2010) Spectral Discrimination of Wild Oat and Canary Grass in Wheat Fields for Less Herbicide Application. Agronomy for Sustainable Development, 30, 689-699. https://doi.org/10.1051/agro/2009052

[27] Fletcher, R.S. (2015) Testing Leaf Multispectral Reflectance Data as Input into Random Forest to Differentiate Velvetleaf from Soybean. American Journal of Plant Sciences, 6, 3193-3204. https://doi.org/10.4236/ajps.2015.619311

[28] Fletcher, R.S. and Turley, R.B. (2017) Employing Canopy Hyperspectral Narrowband Data and Random Forest Algorithm to Differentiate Palmer Amaranth from Colored Cotton. American Journal of Plant Sciences, 8, 3258-3271. https://doi.org/10.4236/ajps.2017.812219 
[29] Deng, W., Huang, Y., Zhao, C., Chen, L. and Wang, X. (2015) Bayesian Discriminant Analysis of Plant Leaf Hyperspectral Reflectance for Identification of Weeds from Cabbages. African Journal of Agricultural Research, 1, 551-562. https://doi.org/10.5897/AJAR2015.10395

[30] Fletcher, R.S. and Turley, R.B. (2018) Comparing Canopy Hyperspectral Reflectance Properties of Palmer amaranth to Okra and Super-Okra Leaf Cotton. American Journal of Plant Sciences, 9, 2708-2718. https://doi.org/10.4236/ajps.2018.913197

[31] McCoy, R.M. (2005) Field Methods in Remote Sensing. The Guilford Press, New York.

[32] Prasad, K.A., Gnanappazham, L., Selvam, V., Ramasubramanian, R. and Kar, C.S. (2015) Developing a Spectral Library of Mangrove Species of Indian East Coast using Field Spectroscopy. Geocarto International, 30, 580-599. https://doi.org/10.1080/10106049.2014.985743

[33] Savitzky, A. and Golay, M.J.E. (1964) Smoothing and Differentiation of Data by Simplified Least Squares Procedures. Analytical Chemistry, 36, 1627-1639. https://doi.org/10.1021/ac60214a047

[34] R Core Team (2019) R: A Language and Environment for Statistical Computing. R Foundation for Statistical Computing, Vienna, Austria. https://www.R-project.org/

[35] Lehnert, L.W., Meyer, H, Obermeier, W.A., Silva, B., Regeling, B., Thies, B. and Bendix, J. (2019) Hyperspectral Data Analysis in R: The Hsdar Package. Journal of Statistical Software, 89, 1-23. https://doi.org/10.18637/jss.v089.i12

[36] Steele, R.G.D. and Torrie, J.H. (1960) Principles and Procedures of Statistics. McGraw-Hill, New York.

[37] Clewer, A.G. and Scarisbrick, D.H. (2001) Practical Statistics and Experimental Design for Plant and Crop Science. John Wiley and Sons, New York.

[38] McHugh, M.L. (2011) Multiple Comparison Analysis Testing in ANOVA. Biochemia Medica, 21, 203-209.

[39] de Mendiburu, F. (2019) Agricolae: Statistical Procedures for Agricultural Research. R Package version 1.3-1. https://CRAN.R-project.org/package=agricolae

[40] Campbell, J.B. (2002) Introduction to Remote Sensing. Third Edition, The Guilford Press, New York.

[41] Jones, H.G. and Vaughan, R.A. (2010) Remote Sensing of Vegetation. Oxford University Press, New York.

[42] Horler, D.N.H., Dockray, M. and Barber, J. (1983) The Red Edge of Plant Leaf Reflectance. International Journal of Remote Sensing, 4, 273-288. https://doi.org/10.1080/01431168308948546

[43] Thenkabail, P.S., Glumma, M.K., Teluguntla, P. and Mohammed, I.A. (2014) Hyperspectral Remote Sensing of Vegetation and Agricultural Crops. Photogrammetric Engineering and Remote Sensing, 80, 697-709. 